International Journal of Engineering \& Technology, $7(2.29)(2018) 871-875$
International Journal of Engineering \& Technology
SPC
Website: www.sciencepubco.com/index.php/IJET
Research paper

\title{
Hospital Information Systems (HIS) in the Examination Rooms and Wards: Doctors Perceived Positive Impact on Quality of Care and Patient Safety
}

\author{
Lizawati Salahuddin $^{1 *}$, Zuraini Ismail ${ }^{2}$ \\ ${ }^{1}$ Faculty of Information and Communication Technology, Universiti Teknikal Malaysia Melaka [Utem], Melaka, Malaysia \\ ${ }^{2}$ Advanced Informatics School [AIS], Universiti Teknologi Malaysia [UTM], Kuala Lumpur, Malaysia \\ *Corresponding Author E-Mail: Lizawati@Utem.Edu.My
}

\begin{abstract}
Hospital Information Systems [HIS] is developed to support healthcare organizations in providing efficient, quality, and safe healthcare services. The objective of this study is to identify and describe doctors' perspective on the impact of HIS use in the examination rooms and wards on quality of care and patient safety. Semi-structured interviews were carried out with thirty one doctors from three Malaysian government hospitals. Thematic qualitative analysis was performed by using ATLAS.ti to deduce the relevant themes. HIS were commonly believed to improve quality of care and patient safety in terms of : [1] accessibility of patients' record, [2] efficient patient-care, [3] well-structured report viewing, [4] less missing patients' records, [5] legibility of patients' records, and [6] safety features. In conclusion, the use of HIS in examination rooms and wards suggests to improve the quality of care and patient safety.
\end{abstract}

Keywords: Hospital Information Systems; safe use; error; patient safety; quality of care

\section{Introduction}

Hospital Information System [HIS] is a computerized integrated information system that manages hospitals' administrative, financial, and medical information [1]. HIS comprises of a variety of hospital information processing systems [2,3]. The typical subsystems of HIS include Administrative Information System [AIS], Patient Care Information System [PCIS], Computerized provider [or physician] order entry [CPOE], Clinical Decision Support System [CDSS] Picture Archiving Management System [PACS], Clinical Information System [CIS], Pharmacy Information System [PIS], Laboratory Information System [LIS], and Radiology Information System [RIS]. Main functions of HIS are patients' admission, planning and organization of patient treatment, clinical order entry, handling electronic patient record, and hospital administrative [4].

Over the past decades, there has been a notable upsurge effort in promoting the adoption of HIS in the healthcare services. Government as well as the private sector have encouraged the implementation of HIS. National large-scale for healthcare computerized systems development projects in the United Kingdom [UK] have been initiated since 1998 [5]. The most important act in encouraging hospitals in the United State [US] to implement the electronic health records [EHRs] by the year 2011 and meaningful use of EHRs was the Health Information Technology for Economic and Clinical Health Act [HITECH]. Under HITECH, economic incentives have been provided for healthcare providers to meaningful use of EHRs, whilst financial penalties by 2015 for hospitals that fail to comply. Similarly, Canada Health Infoway plan was set out in 2001 as an approach to improve patient safety through the implementation of national interoperable EHR [6]. In
Malaysia, the advancement of health system by means of IT has been aspired through Vision 2020. To foster this vision, Multimedia Super Corridor [MSC] project was launched in 1996 with the main objective to transform the nation's economy by the efficient utilization of ICT. The Telehealth Flagship Applications is one of the MSC flagship applications to provide an accessible, integrated, high quality, and reasonable healthcare system. Under the Telehealth Flagship Applications, the Ministry of Health Malaysia $[\mathrm{MOH}]$ has embarked on introducing HIS in several government hospitals [7].

\section{Literature Review}

HIS transforms paper-based healthcare record to an electronic healthcare record. The transformation is expected to improve the quality of healthcare services. Doctors commonly use HIS in examination rooms and wards to view patients' records, enter patients' notes, and make order such as X-ray, medication, and laboratory investigation. Among the benefits of HIS include increased accessibility, legibility, time savings, continuity of care, ability to remotely access clinical data, and facilitated searching, sharing, and protection of electronic data [8]. Furthermore, IT strategies to prevent errors and adverse events include functions that are able to enhance communication, provide access to reference information, support for requiring information and automated calculations, assist with monitoring, and provide decision support [9].

CPOE that is integrated with CDSS, EMR, LIS and radiological provide a powerful system for reducing errors and improving medication safety $[10,11]$. Several benefits of the system include delivering timely medication information, perform background checking such as patient's weight, allergies, laboratory results and 
drug interactions, provide decision support about suitability or correctness of medications, enhance quality measurement, and billing [10]. Healthcare computerised system that calculated and suggested suitable doses, routes, and frequencies have significantly reduced the chances of a prescriber to select wrong values [10] Moreover, basic CDSSs may help in medication selection, dosing, and frequency, whereas sophisticated CDSSs may combine patient-specific or pathogen-specific information and suggest advice to healthcare practitioners [10].

Using panel data from Pennsylvania hospitals from 2005 to 2012, Hydari et al. [2014] investigated the impact of advanced EMR on patient safety. They defined advanced EMR as CPOE and Physician Documentation [PD]. The evaluation focused on medication errors; error in procedure, treatment, or test; and complications of procedure, treatment, or test. They found that the hospitals' adoption of advanced EMRs has a positive impact on patient safety. In overall, the safety events dropped by $27 \%$, which is driven by a decline in several main subcategories including $30 \%$ and $25 \%$ decline in events due to medication errors and complications, respectively. The study provides evidence that hospitals' adoption of advanced EMRs improves patient safety.

In a more recent study, an observational study was conducted to evaluate the impact of CPOE on the medication error rate in an orthopaedic surgery unit at a 700-bed teaching hospital in Paris, France [13]. The observation involved three stages of medication process, namely, prescription, dispensing, and administration during the pre and post-CPOE period. The study findings indicated that there is a significant $92 \%$ decrease in prescribing errors, and $17.5 \%$ significant reduction in administration errors after the implementation of CPOE. The study outcomes advocate that CPOE is a useful system for the improvement of the quality and safety of medication management.

Despite the potential benefits offered by the HIS, it was reported that almost $85 \%$ of Malaysian government hospitals are delaying implementation of the HIS since the Telehealth project was launched [14]. Health care providers' perceptions and preferences about the new technology are likely to affect their adoption [15] The importance of user's perceptions in the new technologies is highlighted in the Technology Acceptance Model [TAM] and its extension [16-18]. Relative advantage [i.e. the degree to which an innovation is perceived as better than its precursor] [14], perceived benefits [Gagnon et al., 2010], and usefulness [i.e. the degree to which a person believes that using a particular technology will enhance his or her job performance] [Gagnon et al., 2012; Gagnon et al., 2010] of the HIS are the important factors that facilitate the adoption of HIS. Previous studies have shown that higher perceived usefulness increase adoption of technology by the healthcare providers [21-23]. Gaining insight into health care providers' perceptions is vital to understand their attitude towards the HIS. Hence, this study was carried out to identify and describe medical doctors' perception on the benefits of HIS implementation in three government Malaysian hospitals. This study was concentrated on its impact to the quality of care and patient safety.

\section{Methodology/Materials}

Qualitative research methods was applied to achieve the objective of this study. The details of the research methods applied for this study are described in the following sections.

\subsection{Sample}

Doctors from three government hospitals which had implemented Total Hospital Information Systems [THIS] were chosen for the semi-structure interviews. All the hospitals were located within the Federal Territory and the Selangor state. Hospital A consists of 562 beds, while both Hospital B and C have 620 beds. Hospital C implemented a complete THIS in February 2008 which is 2 months after Hospital A and B. Therefore, it is anticipated that all the three hospitals have similar working environment and experience of THIS implementation. Table 1 summarises the criteria of the three Malaysians government hospitals that were selected for this research.

Table1: Criteria of Selected Hospitals

\begin{tabular}{|l|l|l|l|}
\hline \multirow{2}{*}{ Criteria } & \multicolumn{3}{|c|}{ Hospital } \\
\cline { 2 - 4 } & A & B & C \\
\hline Number of beds & 562 & 620 & 620 \\
\hline Reference centre & Haematology & $\begin{array}{l}\text { Cardiology, } \\
\text { cardiothoracic, } \\
\text { urology and } \\
\text { nephrology } \\
\text { surgery }\end{array}$ & $\begin{array}{l}\text { Infection dis- } \\
\text { eases, neuro- } \\
\text { surgery, maxil- } \\
\text { lofacial sur- } \\
\text { gery, plastic } \\
\text { surgery, ortho- } \\
\text { paedic and } \\
\text { traumatology }\end{array}$ \\
\hline $\begin{array}{l}\text { THIS implemen- } \\
\text { tation }\end{array}$ & $\begin{array}{l}\text { December } \\
2007\end{array}$ & December 2007 & February 2008 \\
\hline
\end{tabular}

Purposeful sampling was adopted which identifies a sample that best represents or provides information about the research interest [24]. The criteria for a sample selection of this study was based on the time duration of using HIS, by which a minimum one year experience in using HIS.

\subsection{Procedure}

Prior to the data collection, an ethics approval from Malaysia's Ministry of Health Medical Review and Ethics Committee [MREC] was obtained. The semi-structured interviews session involved 31 doctors who have directly used THIS were conducted between 23th March and 18th May 2015 through face-to-face meetings. The interview study was conducted according to procedural steps as suggested by [25]. All the potential respondents were contacted to request their agreement to participate in the interview. They were also briefly explained about the interview. Once they agreed to participate in the interview, an interview appointment was scheduled. The date, time and venue of the session that are convenient for the respondents were decided. A follow-up reminder through the phone was done a day before the session to remind them of the session as well to confirm their attendance. The interviews were all tape-recorded with the respondents who gave their permissions. Each of the interviews lasted between fifteen to ninety minutes.

\subsection{Analysis}

After the semi-structured interviews, audio recorded data and handwritten notes gained from the interviews were transcribed to word processor text. Transcripts of interviews were then presented to the respondents for validation purposes to ensure that the interview transcripts had captured the intended meaning of the respondents. Next, the transcribe interviews were coded in a qualitative data analysis software, ATLAS.ti. The interviews transcripts were read repeatedly to highlight parts of the text and to emphasise the sections and issues that seemed to be important and relevant. The transcripts were divided into text segments and these segments were labelled with codes. The coded data were reviewed to identify areas of similarity and overlap between codes. Codes that seem to share some unifying feature were clustered into a themes [26].

\section{Results and Findings}

\subsection{Respondents' Profile}

Overall, 31 medical doctors took part in the interview. There were 10, 9, and 12 respondents from Hospital A, B, and C, respectively. Of the respondents, 58 percent were the male. The respondents were from numerous departments comprising emergency and trauma, medical, general surgery, paediatric, obstetrics and gynaecology, orthopaedic, otorhinolaryngology, ophthalmology, cardiology, nephrology, neurosurgery and neurology, haematology, psychiatric, and rehabilitation. They use HIS to support their rou- 
tine patient-care activities in both examination rooms and wards. They had an average of 4 years of using HIS. Therefore, the respondents have adequate experience to elicit their views on the benefits of HIS implementation. Table 2 presents the details of respondents participated in the interview.

Table2: Respondents' Details

\begin{tabular}{|c|c|c|c|c|}
\hline $\begin{array}{l}\text { Hos- } \\
\text { pital }\end{array}$ & $\begin{array}{c}\text { Re- } \\
\text { spond- } \\
\text { ent }\end{array}$ & $\begin{array}{l}\text { Gen- } \\
\text { der }\end{array}$ & Department & $\begin{array}{c}\text { HIS Experience } \\
\text { [year] }\end{array}$ \\
\hline \multirow{10}{*}{ A } & $1 \mathrm{a}$ & $\begin{array}{l}\text { Fe- } \\
\text { male }\end{array}$ & $\begin{array}{l}\text { Obstetrics and Gy- } \\
\text { naecology }\end{array}$ & 7 \\
\hline & $2 a$ & $\begin{array}{l}\text { Fe- } \\
\text { male }\end{array}$ & $\begin{array}{l}\text { Obstetrics and Gy- } \\
\text { naecology }\end{array}$ & 2.5 \\
\hline & $3 a$ & Male & Medical & 2.5 \\
\hline & $4 a$ & Male & Orthopaedic & 2 \\
\hline & $5 a$ & $\begin{array}{l}\text { Fe- } \\
\text { male }\end{array}$ & Otorhinolaryngology & 8 \\
\hline & $6 a$ & $\begin{array}{l}\mathrm{Fe}- \\
\text { male }\end{array}$ & Otorhinolaryngology & 4 \\
\hline & $7 \mathrm{a}$ & Male & $\begin{array}{l}\text { Emergency and } \\
\text { Trauma }\end{array}$ & 1.5 \\
\hline & $8 \mathrm{a}$ & $\begin{array}{l}\mathrm{Fe}- \\
\text { male }\end{array}$ & Orthopaedic & 8 \\
\hline & $9 \mathrm{a}$ & Male & Haematology & 2.5 \\
\hline & $10 \mathrm{a}$ & Male & General Surgery & 4 \\
\hline \multirow{12}{*}{ B } & $1 b$ & $\begin{array}{l}\mathrm{Fe}- \\
\text { male }\end{array}$ & Paediatric & 8.5 \\
\hline & $2 b$ & Male & Orthopaedic & 3 \\
\hline & $3 b$ & $\begin{array}{l}\mathrm{Fe}- \\
\text { male }\end{array}$ & Ophthalmology & 6 \\
\hline & $4 b$ & $\begin{array}{l}\text { Fe- } \\
\text { male }\end{array}$ & Paediatric & 6 \\
\hline & $5 b$ & Male & Cardiology & 3 \\
\hline & $6 b$ & Male & Orthopaedic & 2 \\
\hline & $7 b$ & $\begin{array}{l}\mathrm{Fe}- \\
\text { male }\end{array}$ & General Surgery & 10 \\
\hline & $8 \mathrm{~b}$ & Male & Nephrology & 4 \\
\hline & $9 b$ & $\begin{array}{l}\mathrm{Fe}- \\
\text { male }\end{array}$ & Ophthalmology & 5 \\
\hline & $10 \mathrm{~b}$ & $\begin{array}{l}\mathrm{Fe}- \\
\text { male }\end{array}$ & Cardiology & 5 \\
\hline & $11 b$ & Male & $\begin{array}{l}\text { Emergency and } \\
\text { Trauma }\end{array}$ & 2 \\
\hline & $12 b$ & Male & $\begin{array}{l}\text { Emergency and } \\
\text { Trauma }\end{array}$ & 2.5 \\
\hline \multirow{9}{*}{$\mathrm{C}$} & $1 \mathrm{c}$ & $\begin{array}{l}\mathrm{Fe}- \\
\text { male }\end{array}$ & $\begin{array}{l}\text { Obstetrics and Gy- } \\
\text { naecology }\end{array}$ & 4.5 \\
\hline & $2 \mathrm{c}$ & $\begin{array}{l}\mathrm{Fe}- \\
\text { male }\end{array}$ & Rehabilitation & 2 \\
\hline & $3 \mathrm{c}$ & $\begin{array}{l}\mathrm{Fe}- \\
\text { male }\end{array}$ & Rehabilitation & 2 \\
\hline & $4 \mathrm{c}$ & Male & Psychiatric & 2 \\
\hline & $5 c$ & $\begin{array}{l}\mathrm{Fe}- \\
\text { male }\end{array}$ & $\begin{array}{l}\text { Emergency and } \\
\text { Trauma }\end{array}$ & 4.5 \\
\hline & $6 c$ & $\begin{array}{l}\mathrm{Fe}- \\
\text { male }\end{array}$ & Orthopaedic & 3 \\
\hline & $7 \mathrm{c}$ & $\begin{array}{l}\mathrm{Fe}- \\
\text { male }\end{array}$ & Medical & 2.5 \\
\hline & $8 \mathrm{c}$ & Male & $\begin{array}{l}\text { Neurosurgery and } \\
\text { Neurology }\end{array}$ & 2 \\
\hline & $9 \mathrm{c}$ & $\begin{array}{l}\mathrm{Fe}- \\
\text { male }\end{array}$ & Paediatric & 3 \\
\hline
\end{tabular}

\subsection{HIS Impact on Quality of Care and Patient Safety}

Six themes with regard to the positive impact on quality of care and patient safety could be extracted from the interviews; [1] accessibility of patients' records, [2] efficient patient-care, [3] wellstructured report viewing, [4] less missing patients' records, [5] legibility of patients' records, and [6] safety features. The themes that emerged from the interviews were generally very similar at all hospitals. The following sections discuss in more detail of each theme.

\subsubsection{Accessibility of Patients' Records}

The respondents remarked that patients' records can be accessed easily and immediately on HIS at anytime and anywhere. Doctors simply key in the patient's ID to access the medical record. Hence, doctors are able to read about their patients' history for more clarification whenever the patients come to the hospital. This view was expressed by two respondents as follows:

"The impact of HIS towards quality of care and patient safety is good because everybody can access the patients' information in which you do not have to wait to trace the record from the medical record department. When patient come, you can immediately search their record and read about their problem." [Respondent 6a] "I can just trace record of any dates without having to do it like back in those days where I had to go to the medical record department and trace it one by one. Now we can just click the record on the spot which is very much easier." [Respondent 4c]

Conversely, using the paper-based approach, patients' records can only be traced at the medical record department during the office hours. The doctors always face problem to trace the paper-based records when patients consult them out of office hours. The patients' records only can be viewed on the next day at the record department if patients come at late night. This view was reported by three respondent as follows:

"For the paper-based, we need to trace the old notes, we need to wait for the office hour, and we need to queue up just to get the old notes, and to search the file. The computer system is much easier to go through the history." [Respondent 7a]

"I can just trace record of any dates without having to do it like back in those days where I had to go to the medical record department and trace it one by one. Now we can just click the record on the spot which is very much easier." [Respondent 4c]

"I think the system is good because you can track the old records, say for example, when the patient comes at 12.30 in the midnight. So, you at least have a few ideas about the patient because he sometimes do not really know or understand his condition. You can clarify with the patient. Compared to the manual, you have to wait for the working hours then only you can trace the record." [Respondent 9c]

Moreover, a respondent highlighted that it is time consuming and difficult to trace a paper-based patient record because the record may be placed at other department where he previously visit.

"We can also access the information in shorter time with HIS. Unlike manual, it is difficult to find record because patient may come many times but the record is placed at other location. Conversely, the list of dates that have been visited by the patients as well the diagnosis are stated in the system. Therefore it is clearer." [Respondent 5c]

\subsubsection{Efficient Patient-care}

The respondents inferred that patient-care has become more efficient with the implementation of HIS. Investigation results and medical history become immediately visible when viewed on HIS. Unlike paper-based, they sometimes had to go to the laboratory for multiple times to trace the results. This finding is illustrated by comments from two respondents who said that:

"You know exactly the medication, the blood test result as they come out immediately in the computer system without having to retrieve the results manually. It terms of patient-care, it is much more efficient." [Respondent 10b]

"For manual, it takes time for you to write the forms, take the blood, send to the lab and then go to the lab again two to three times to trace the results. Unlike HIS where you just send the blood and the results you can just look at the computer." [Respondent $5 \mathrm{~b}]$

Moreover, some of the information especially medication are already available in the system. List of medication appears immediately from the HIS facilitating doctors to order medication. Doctors need not to write the medication names which sometimes they confuse with the exact spelling. Besides, doctors can check the 
availability of the medication stock thru the HIS. With these information, HIS helps to speed up the medication ordering process. A respondent explained this view as:

"Sometimes it can be quite fast in terms of ordering. For example the list of drug appears immediately. Sometimes we are not sure of the medication spelling. We can easily check the proper and exact medication name in the systems. We can also trace in the systems whether the medication stock is available or not. Unlike manual, it takes longer time." [Respondent 9c]

Pharmacists also able to check the medication that have been prescribed previously and medical record's history of the related patient. They immediately received the medication order made via HIS. Consequently, patients can immediately go to the pharmacy to collect their medication. Hence, prescribing medication by using HIS resulted in less time and error compared to the handwritten prescription. This view was reported by a respondent as follows:

"With the HIS you have the ability to look back of the old history of medication that have been prescribed before, the old notes and every history of admissions so that it really helps us in managing patient efficiently and being able to order the medication through the system without having to write prescription and it goes straight to the pharmacy, that save a lot of time and less error in term of that." [Respondent 10b]

Besides that, doctors do not need to repeatedly key in the patient's profile to order medication, $\mathrm{x}$-ray, and laboratory examination of the corresponding patient because it is already available on HIS. It reduces the doctors' time and workload to key in the patient's profile for the ordering tasks. Therefore, patient-care activities can be done quicker with HIS compared to the manual system. The view was pointed out by one respondent as follows:

"HIS facilitates us in ordering process. It lessens our ordering time in which we do not have to type all the information such as the patient's profile as it is already in the system compared to the paper-based." [Respondent 1b]

\subsubsection{Well-structured Report Viewing}

Patient progress report can be reviewed from the HIS in a more structured format compared to the paper-based. The well-arranged report facilitates the doctors to make comparison of the patient progress of different date. Unlike paper-based approach, doctors need to review on different sheets according to the date in order to look at the patient progress. Two respondents conveyed the view as follows:

"We can also easily trace the blood results for yesterday and today. It is automatically tabled nicely in the system." [Respondent 3a]

"We can easily search lab results, compare the results with previous results of different dates compare to the paper-based system. The results are well arranged to assist for the results review." [Respondent $1 \mathrm{~b}]$

\subsubsection{Less Missing Patients' Records}

Patients' records and laboratory examination results are crucial to plan the patient-care. Without these information the patient-care may not be accurate. Patients' records may be referred by multiple departments when the patients undergo several different illnesses. There are high possibility of missing hardcopy patients' records or laboratory results especially when it carried to multiple departments. Contrariwise, patients' records in the HIS rarely lost because all the records are centralized in one database. The view is explained by two respondents as follows:

"The order through system cannot be lost. The order straight away reach to the related department such as pathology and imaging unless the person did send the specimen. Likewise the notes will not be missing. On the other hand, paper order can be lost at anywhere." [Respondent 7b]

"The advantage of HIS is that whenever patient comes such as in the evening, late night, or morning at any department like emergency, we can view his history notes. For the manual, the records can be lost or placed at the location where he previously visit." [Respondent 7c]

\subsubsection{Legibility of Patients' Records}

The respondents believed that HIS is better than handwritten documentation, in terms of legibility of the notes or order entry. They always find it difficult to understand the others' handwriting, and might possibly interpret it wrongly. On the other hand, it is easy to read the standard character shown on HIS, and consequently reduce error. Based on that perspective, the respondents believe that HIS could contribute to a safer patient-care compared to the paperbased approached. This inference was conveyed by three respondents who said that:

"It is difficult to understand others' handwriting. It takes time to understand. Sometimes we may interpret it wrongly. Unlike HIS, the typing is clear and easy to understand. Even though there is typing error, we can still read it and grasp the meaning." [Respondent 5a]

"For the manual procedure, you have problem with the spelling and the person who reads the hand writing may not understand it. In terms of that, HIS is better and safer." [Respondent 7a]

"In terms of readability, it is easy to read the standard character from the computer compared to the handwriting. Looking from that perspective, HIS is better than the manual approaching in terms of reducing error." [Respondent 7c]

\subsubsection{Safety Features}

HIS is beneficial to the patient's safety because it provides alert or suggestion to the users. In relation to medication, HIS provides suggestion on the dosage amount, medication alert, and medication allergy that facilitates to prevent medication error. Besides, HIS also offers a reminder of pregnant women while ordering for $\mathrm{x}$-ray. The alert is helpful for the users to proceed with the precautionary action. On the contrary, these facilities are absent in the paper-based approach. This view was expressed by three respondents as follows:

"The advantage of HIS is that it is safer than hand writing. For example, when we order medication, HIS automatically suggests the dosage amount. Therefore, dosage error may not happen." [Respondent 4a]

"When we open a patient's notes, the notes are displayed on the screen if the patient has allergy. We also have alert for medication. You just need to click on it, and then the system will inform us about it. Compared to the manual procedure, we do not have such facility unless the patient informs us about the allergy. That is the obvious benefits of HIS." [Respondent 9c]

"For the medication, HIS provide default dosage which is very helpful. Our pharmacists are very good because they usually call us for unusual cases. For the x-ray order, it has a pop-up asking whether the patient is pregnant or not which helps to remind us. Unlike doing it manually, we may forget such things. Overall HIS helps to improve quality of care and safety of patients." [Respondent 9b]

\section{Discussion}

The interview findings revealed that majority of the respondents perceived HIS contributes to the quality of care and patient safety. HIS enable the doctors to access patients' records easily and immediately at any time. The internet-based communication reduced the amount of time spent searching for files. It allows healthcare providers to get critical medical information about their patients immediately when it is required [27]. Hence, HIS allowed the continuity of patient-care. Moreover, patient-care management is more efficient with HIS. The investigation results and medical history become promptly visible on HIS which accelerates the patient-care delivery. Subsequently, it reduces the waiting time to view the medical records. In addition, HIS minimize the doctor's load and time whereby they do not need to repeatedly key in pa- 
tient's profile to request medication, $\mathrm{x}$-ray, and laboratory examination. Additionally, the medical reports are well-structured on the HIS, thus this facilitate doctors to make comparison of the patients' progress of different date. Similarly, it is expected less possibility of missing patients' records as all records are stored in a centralize database. It reduces the tendency of misplacement of records due to human error. The availability of patients' records is crucial as doctors' precise decisions would consequently lead to quality healthcare services and successful medical treatment. Besides, legibility of the patients' notes or order entry via HIS is better in comparison to handwritten document. Thus, wrongly interpretation of patients' notes or order entry would be avoided. A study was conducted to evaluate the relation between the quality of patient records and the occurrence of adverse events [28]. The study shows that poor quality [completeness, legibility and adequacy] of the available patient information was related with higher rates of adverse events. Likewise, another study discovered a high incident of medication documentation error due to the bad handwritten prescription [29]. In addition, HIS contributes to the patients' safety as it offers safety features such as the default dosage amount and alert. The safety features help to prompt or avert users from making mistakes. On the other hand, safety alert is absent in the paper-based approach. Similarly, using panel data from Pennsylvania hospitals from 2005 to 2012, Hydari et al. [12] found that the hospitals' adoption of advanced EMRs has a positive impact on patient safety.

This study has several limitations. The first relates to the unit analysis, this only focus from the doctors' perspective. Other group of HIS users such as nurses and pharmacist were not considered in this study. Their inclusion may provide broad and indepth information to the study. The second limitation which is the findings of this study merely based on the perceptions of HIS users. The hospital records and evidence on safety were not analyzed in this study. The result might differ from the actual impact. Observation and document review analysis are recommended for the future study in order to gain further understanding on the HIS impact on quality of care and patient safety.

\section{Conclusion}

Despite steady HIS adoption in Malaysia, most of the respondents' perceived positive impact of HIS on quality of care and patient safety. HIS improves the quality of care due to the accessibility, efficient patient-care management, well-structured report viewing, and less missing patients' records. In addition, HIS contributes to the patients' safety as it offers safety features and legible patients' records. Therefore, more effort is necessary to accelerate the adoption of HIS among healthcare providers in Malaysia as HIS has significant potential in enhancing quality of care and patient safety.

\section{Acknowledgement}

This work was supported by Universiti Teknologi Malaysia [UTM] research grant Q.130000.2538.11H82, Universiti Teknikal Malaysia Melaka [UTeM], and Ministry of Higher Education [MOHE] Malaysia.

\section{References}

[1] Abdullah ZS. Hospital information systems implementation framework: critical success factors for Malaysian public hospitals. Curtin University; 2013.

[2] Yusof MM, Papazafeiropoulou A, Paul RJ, Stergioulas LK. Investigating evaluation frameworks for health information systems. Int J Med Inform. 2008 Jun;77[6]:377-85.

[3] Masrom M, Rahimly A. Overview of Data Security Issues in Hospital Information Systems. Pacific Asia J Assoc Inf Syst. 2015;7[4]:51-65.

[4] Ammenwerth E, Winter A. Strategic information management in hospitals: an introduction to hospital information systems. Springer; 2004.

[5] Waterson P. Health information technology and sociotechnical systems: a progress report on recent developments within the UK National Health Service [NHS]. Appl Ergon. Elsevier Ltd; 2014 Mar;45[2]:150-61.

[6] Rozenblum R, Jang Y, Zimlichman E, Salzberg C, Tamblyn M, Buckeridge D, et al. A qualitative study of Canada's experience with the implementation of electronic health information technology. Can Med Assoc J. 2011:183[5]:E281-8.

[7] Mohan J, Razali Raja Yaacob R. The Malaysian Telehealth Flagship Application: a national approach to health data protection and utilisation and consumer rights. Int J Med Inform. 2004 Mar;73[3]:217-27.

[8] Black AD, Car J, Pagliari C, Anandan C, Cresswell K, Bokun T, et al. The impact of eHealth on the quality and safety of health care: a systematic overview. PLoS Med. 2011 Jan;8[1]:e1000387.

[9] Bates DW, Gawande AA. Improving safety with information technology. N Engl J Med. 2003 Jun;348[25]:2526-34.

[10] Kaushal R, Bates DW. Information technology and medication safety: what is the benefit? Qual Saf Health Care. 2002 Sep;11[3]:261-5.

[11] Mahoney CD, Berard-Collins CM, Coleman R, Amaral JF, Cotter CM Effects of an integrated clinical information system on medication safety in a multi-hospital setting. Am J Heal Pharm. 2007 Sep;64[18]:1969-77.

[12] Hydari MZ, Telang R, Marella WM. Saving Patient Ryan - Can Advanced Electronic Medical Records Make Patient Care Safer? Soc Sience Res Netw. 2014;

[13] Hernandez F, Majoul E, Montes-palacios C, Antignac M, Hejblum G, Fernandez C, et al. An Observational Study of the Impact of a Computerized Physician Order Entry System on the Rate of Medication Errors in an Orthopaedic Surgery Unit. PLoS One. 2015;10[7]:1-12.

[14] Ahmadi H, Nilashi M, Ibrahim O. Organizational decision to adopt hospital information system: An empirical investigation in the case of Malaysian public hospitals. Int J Med Inform. Elsevier Ireland Ltd 2015;84[3]:166-88.

[15] Zwaanswijk M, Verheij RA, Wiesman FJ, Friele RD. Benefits and problems of electronic information exchange as perceived by health care professionals: an interview study. BMC Health Serv Res. 2011 Jan;11:256.

[16] Davis FD. Perceived usefulness, perceived ease of use, and user acceptance of information technology. MIS Q. 1989;319-40.

[17] Venkatesh V, Davis FD. A theoretical extension of the technology acceptance model: four longitudinal field studies. Manage Sci. 2000;46[2]:186-204.

[18] Venkatesh V, Morris MG, Davis GB, Davis FD. User acceptance of information technology: toward a unified view. MIS Q. 2003;425-78.

[19] Gagnon MP, Pluye P, Desmartis M, Car J, Pagliari C, Labrecque M, et al. A systematic review of interventions promoting clinical information retrieval technology [CIRT] adoption by healthcare professionals. Int J Med Inform. Elsevier Ireland Ltd; 2010;79[10]:669-80.

[20] Gagnon M-P, Desmartis M, Labrecque M, Car J, Pagliari C, Pluye P, et al. Systematic Review of Factors Influencing the Adoption of Information and Communication Technologies by Healthcare Professionals. J Med Syst. 2012;36[1]:241-77.

[21] Iqbal U, Ho $\mathrm{CH}$, Li YC, Nguyen PA, Jian WS, Wen HC. The relationship between usage intention and adoption of electronic health records at primary care clinics. Comput Methods Programs Biomed Elsevier Ireland Ltd; 2013;112 [3]:731-7.

[22] McGowan BS, Wasko M, Vartabedian BS, Miller RS, Freiherr DD, Abdolrasulnia M. Understanding the Factors That Influence the Adoption and Meaningful Use of Social Media by Physicians to Share Medical Information. J Med Internet Res. 2012;14[5]:e117.

[23] Villalba-Mora E, Casas I, Lupianez-Villanueva F, Maghiros I. Adoption of health information technologies by physicians for clinical practice: The Andalusian case. Int J Med Inform. 2015;84[7]:477-85.

[24] Singh YK. Fundamental of Research Methodology and Statistics. New Age International [P] Ltd.; 2006.

[25] Hesse-Biber SN, Leavy P. The Practice of Qualitative Research. SAGE Publications, Inc; 2006.

[26] Braun V, Clarke V. Using thematic analysis in psychology. Qual Res Psychol. 2006;3[2]:77-101.

[27] Lee OF, Meuter ML. The adoption of technology orientation in healthcare delivery: Case study of a large-scale hospital and healthcare system's electronic health record. Int J Pharm Healthc Mark. 2010;4[4]:355-74.

[28] Zegers M, de Bruijne MC, Spreeuwenberg P, Wagner C, Groenewegen PP, van der Wal G. Quality of patient record keeping: an indicator of the quality of care? BMJ Qual Saf. 2011 Apr;20[4]:314-8

[29] Hartel MJ, Staub LP, Röder C, Eggli S. High incidence of medication documentation errors in a Swiss university hospital due to the handwritten prescription process. BMC Health Serv Res. BioMed Central Ltd; 2011;11[199]:1-6. 